\title{
Failure of BCL-2 Up-Regulation in Proximal Tubular Epithelial Cells of Donor Kidney Biopsy Specimens Is Associated with Apoptosis and Delayed Graft Function
}

\author{
Christoph Schwarz, Peter Hauser, Rudolf Steininger, Heinz Regele, Georg Heinze, \\ Gert Mayer, and Rainer Oberbauer
}

Department of Internal Medicine III (CS, PH, RO), Division of Nephrology, and Departments of Transplant Surgery (RS), Ultrastructural Pathology (HR), and Medical Computer Sciences (GH), University of Vienna, Vienna, and Division of Nephrology (GM), University of Innsbruck, Innsbruck, Austria

\begin{abstract}
SUMMARY: In renal transplantation, postischemic acute renal failure (ARF) develops in more than $20 \%$ of patients. We investigated whether tubular epithelial cells obtained from donor kidneys without subsequent ARF express a different pattern of survival genes, compared with cells from kidneys exhibiting ARF. Donor kidney biopsy specimens were obtained before transplantation from eight recipients of cadaveric kidneys with primary graft function (CAD-PF), eight patients with biopsy-proven ARF without rejection (CAD-ARF), and eight recipients of living donor kidneys with primary graft function (LIV). One thousand proximal tubular epithelial cells per biopsy specimen were isolated by laser capture microdissection. Quantitative analysis of apoptosis and the apoptosis regulatory genes $\mathrm{Bcl}-2, \mathrm{Bcl}-\mathrm{xL}$, and Bax were performed by terminal deoxynucleotidyl transferasemediated deoxyuridine triphosphate-digoxigenin nick-end labeling staining and real-time PCR, respectively. Primary cultures of human proximal tubular epithelial cells served as calibrator. The number of apoptotic cells was significantly higher in CAD-ARF compared with LIV and CAD-PF ( $1.5 \pm 1.1 \%[p<0.05]$ vs. $0.3 \pm 0.2 \%$ vs. $0.4 \pm 0.2 \%$; mean \pm SD). The apoptosis inhibitors $\mathrm{Bcl}-2$ and $\mathrm{Bcl}-\mathrm{xL}$ were significantly up-regulated in renal tubular cells of recipients without ARF compared with CAD-ARF. The ratios of Bcl-2/GAPDH normalized to calibrator were as follows: LIV $48 \pm 30$, CAD-PF $38 \pm 55$, and CAD-ARF $5 \pm 7$ ( $p<0.05$ ). The corresponding ratios for $\mathrm{Bcl}-\mathrm{xL}$ were as follows: LIV $6 \pm 6, \mathrm{CAD}-\mathrm{PF} 5 \pm 3$, and CAD-ARF $1 \pm 1$ ( $p<0.05)$. No difference in the expression of the proapoptotic Bax could be observed. These data suggest that failure of proximal tubular cells to respond to injury by up-regulation of survival factors from the Bcl-2 family contributes to postischemic ARF in patients after cadaveric renal transplantation. (Lab Invest 2002, 82:941-948).
\end{abstract}

Dostischemic acute renal failure (ARF), which ocplant recipients, is the major risk factor for long-term transplant survival (Hall et al, 1985; Ojo et al, 2001; van Valenberg et al, 1987). Tubular epithelial cells are the primary victims of this ischemic injury. Necrosis of these cells clearly occurs, but removal of sublethally injured tubules by apoptosis is an equally important pathogenic mechanism (Lieberthal and Levine, 1996). The number of apoptotic tubular cells in the donor kidney biopsy specimens is higher than in native kidney ARF and predicts the development of allograft ARF (Oberbauer et al, 1999; Olsen et al, 1989).

Apoptosis is a carefully choreographed, complex process, in which catabolic enzymes finally degrade

DOI: 10.1097/01.LAB.0000021174.66841.4C

Received March 22, 2002.

This work was supported by Else Kröner Fresenius Stiftung, Germany, and Vienna Medical Funds, Grant 1675.

Address reprint requests to: $D r$. Rainer Oberbauer, Universitätsklinik für Innere Medizin III, Abteilung für Nephrologie und Dialyse, Währinger Gürtel 18-20, A-1090 Vienna, Austria. E-mail: RAINER. OBERBAUER@AKH-WIEN.AC.AT essential cellular macromolecules, which leads to a characteristic death phenotype (Cohen, 1993). The $\mathrm{Bcl}-2$ family members are key regulators of this process (Oltvai and Korsmeyer, 1994). Although the exact mechanisms by which the $\mathrm{Bcl}-2$ family regulates apoptosis are not entirely known, it is clear that the susceptibility of cells to apoptosis can be altered by changing the level of expression of individual family member proteins (Oltvai et al, 1993). In contrast to $\mathrm{Bcl}-2$ and $\mathrm{Bcl}-\mathrm{xl}$, Bax acts as a proapoptotic factor. The ratio of expression of $\mathrm{Bcl}-2$ or $\mathrm{Bcl}-\mathrm{xl}$ to Bax seems to determine cell fate in an adverse microenvironment (Ortiz et al, 2000). Thus, for any given apoptotic stimulus, the balance between death and survival seems to be determined by the ratio of apoptosisstimulating and -suppressing Bcl-2 family members (Oltvai and Korsmeyer, 1994).

We have previously shown in a rat model of temporary ischemia to a solitary, healthy kidney that apoptosis of tubular cells after reperfusion mainly occurs within the first 24 hours. However, the long-term consequences (tubular dilation, interstitial fibrosis, and glomerulosclerosis) develop as late as 20 weeks after the insult. Apoptosis in this setting is associated with a relative overexpression of the proapoptotic $\mathrm{Bcl}-2$ 
member Bax compared with antiapoptotic Bcl-2 or $\mathrm{Bcl}-\mathrm{xL}$ (Oberbauer et al, 2001).

In renal transplantation, an adequate response of tubular epithelial cells to ischemia includes an upregulation of survival genes. Gobe et al (2000) showed that the inability of expressing antiapoptotic members of the $\mathrm{Bcl}-2$ family as response to oxidative stress is associated with a higher rate of apoptosis in proximal tubular epithelial cells in vitro (Cuttle et al, 2001).

This study was designed to elucidate whether proximal tubular epithelial cells from donor kidney biopsy specimens obtained before transplantation with subsequent primary graft function exhibit a different expression of antiapoptotic Bcl-2 members, compared with tubular cells of kidneys that displayed succeeding postischemic ARF.

\section{Results}

\section{Apoptosis}

The number of apoptotic tubular epithelial cells in the three groups is depicted in Figure 1A. Living donor kidney biopsy specimens (LIV) and cadaveric kidney biopsy specimens with primary graft function (CADPF) exhibited significantly less apoptotic cells compared with cadaveric donor kidneys with delayed graft function and acute renal failure (CAD-ARF).

\section{Apoptosis Regulatory Genes}

A calibration curve with five different RNA concentrations from calibrator cells was performed in each run. Total RNA from $2 \mathrm{ng}$ to $20 \mu \mathrm{g}$ was used to assess the correct amplification of each gene. The yield of total RNA isolated from 100 tubular cross-sections averaged $64 \pm 37 \mathrm{ng}$.

$\mathrm{Bcl}-2$ was significantly up-regulated in tubular cells of donor kidney biopsy specimens of all groups, compared with calibrator (healthy human tubular epithelial cells). However, donor kidney biopsy specimens with a low number of apoptotic tubular cells and primary graft function after transplantation exhibited nearly 10-fold more Bcl-2 expression (LIV and CAD$\mathrm{PF})$, compared with kidneys with a high percentage of apoptotic cells and subsequent development of postischemic ARF (CAD-ARF). This is illustrated in Figure $1 \mathrm{~B}$.

The other investigated antiapoptotic Bcl-2 member, $\mathrm{Bcl}-\mathrm{xL}$, was also significantly up-regulated in all donor kidney biopsy specimens, compared with calibrator. $\mathrm{Bcl}-\mathrm{xL} / \mathrm{GAPDH}$ was expressed more strongly than calibrator in the LIV group (by $6 \pm 6$-fold), in the CAD-PF group (by $5 \pm 3$-fold), and in the CAD-ARF group (by $1 \pm 1$-fold). The differences between the CAD-ARF group and the other donor groups reached statistical significance in the Kruskall-Wallis test but were not as significant as the Bcl-2 differential regulation.

The investigated proapoptotic gene Bax was significantly up-regulated in all groups compared with calibrator, but no intergroup differences could be detected. Bax/GAPDH was more strongly expressed than calibrator in LIV, CAD-PF, and CAD-ARF by $7 \pm$ 6 -fold, $11 \pm 6$-fold, and $5 \pm 5$-fold, respectively. The overall coefficient of variation of Bcl-2 members and GAPDH triplicate samples was $0.05 \pm 0.02$.

There was a clear difference in the balance of proand antiapoptotic genes among the donor kidney groups. Those kidneys with primary graft function and low levels of apoptosis (LIV, CAD-PF) exhibited an overproportional up-regulation of the survival gene $\mathrm{Bcl}-2$, compared with the death gene Bax. Bcl-2/ GAPDH in kidneys from the CAD-ARF group, on the other hand, was up-regulated only proportional to Bax/GAPDH ( $5 \pm 3$-fold and $5 \pm 5$-fold of calibrator).

There was no correlation between any of the obtained donor and recipient parameters, such as donor age or organ ischemia time and the number of apoptotic cells. Furthermore, the expression of Bcl-2 did not correlate with the duration of cold ischemia (Fig. $1 \mathrm{C)}$.

\section{Discussion}

We have shown that the number of apoptotic tubular epithelial cells in donor kidney biopsy specimens can predict the development of postischemic ARF in man (Oberbauer et al, 1999). The present data support this finding but additionally provide more insight on the regulation of apoptotic cell death on the molecular basis. Those kidneys that cannot adequately respond to donor stress and ischemic injury by unproportional up-regulation of the survival factor Bcl-2, exhibit more apoptotic tubular epithelial cells and subsequently postischemic ARF after transplantation. Discrete simulation of apoptosis regulation by the Bcl-2 family after external stimuli revealed the Key significance of Bcl-2 up-regulation for apoptosis prevention (Siehs et al, 2002). Furthermore, we recently demonstrated that microinjection of a synthetically derived $\mathrm{Bcl}-2$ peptide could prevent renal tubule cell apoptosis in vitro (Peherstorfer et al, 2002).

It is of major importance to avert postischemic ARF and delayed graft function, because they are the most prevalent risk factors for reduced allograft half-life (Ojo et al, 2001). United Network of Organ Sharing data of 86,682 patients showed that the half-life of a cadaveric donor kidney with ARF averages 8.6 years compared with 14.1 years for primarily functioning kidneys (Gjertson, 2000). Recipients of living donor kidneys usually do not exhibit postischemic ARF and have a significantly longer graft half-life (Hariharan et al, 2000). The reasons are not entirely known, but it has been shown in experimental kidney and liver transplantation that brain death causes an autonomic storm followed by structural changes of the transplant organ (Van der Hoeven et al, 1999, 2001). In living donor transplantation, the ability to counterbalance ischemic tubular injury by up-regulation of $\mathrm{Bcl}-2$ member survival genes suggests that an active process of vital cells is present. During cold preservation ex vivo, all active processes are shut off (Salahudeen et al, 2000). Koo et al (1999) demonstrated that renal morphology and HLA-DR protein expression do not 
A TUNEL positive tubular cells

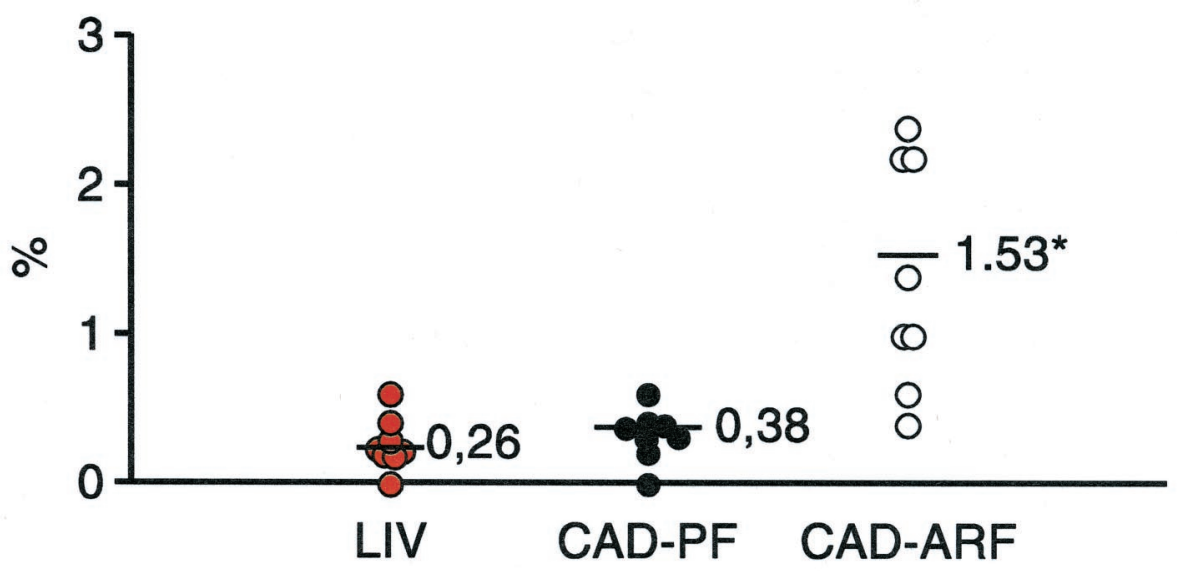

B Bcl-2/GAPDH expression in tubular cells

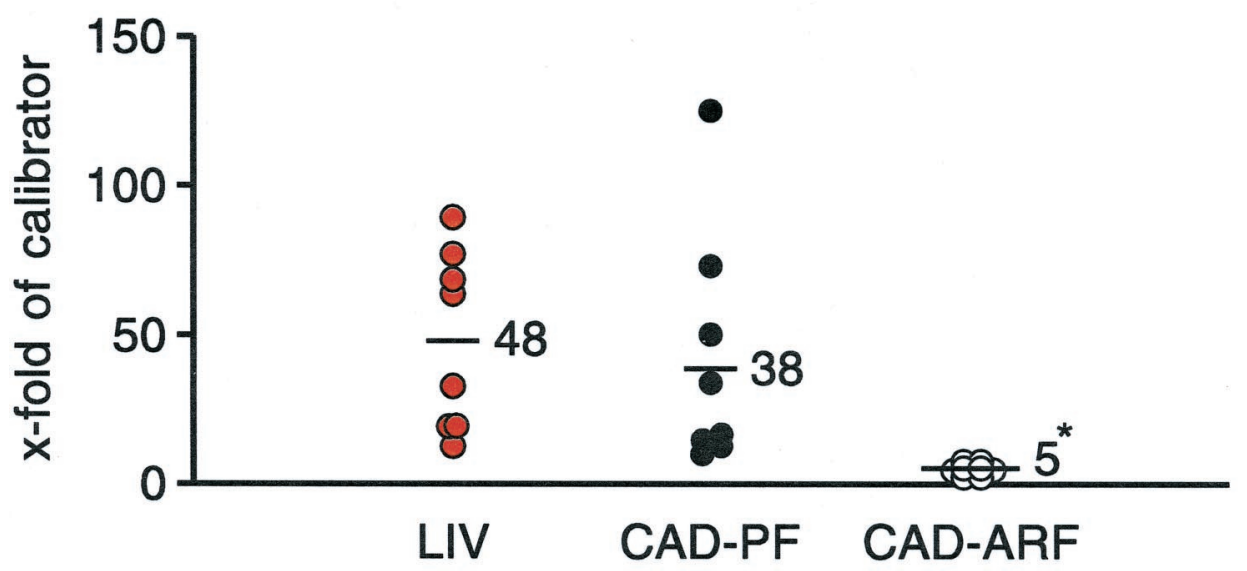

\section{Bcl-2/GAPDH expression in tubular cells in relation to cold ischemia time}

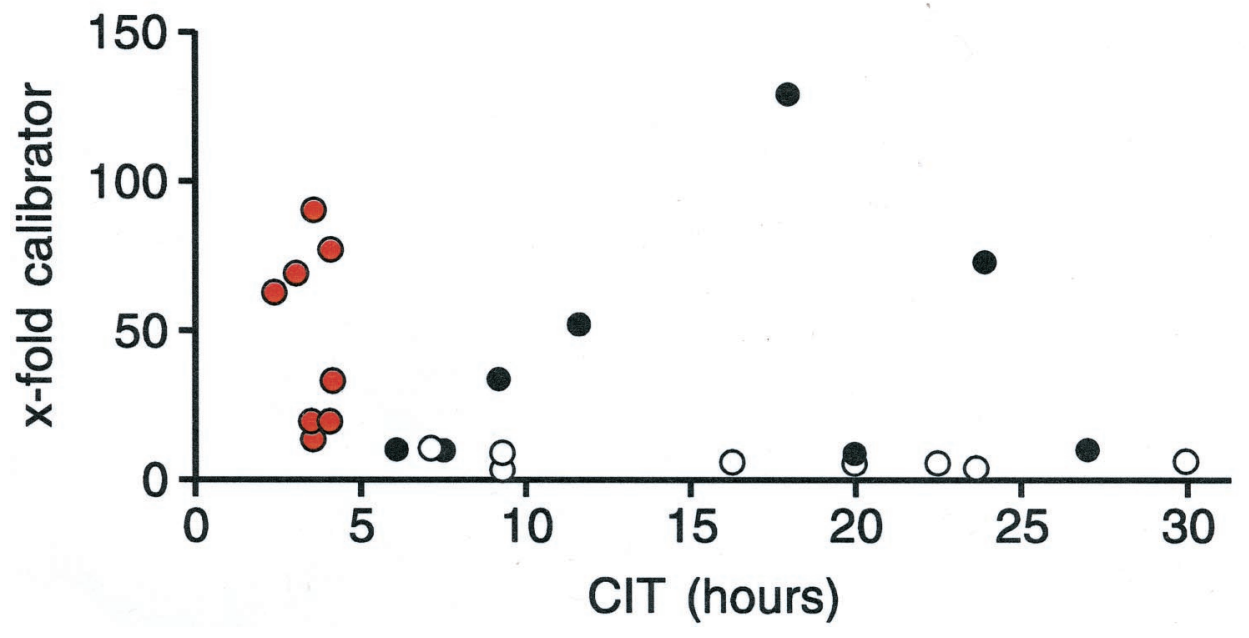

Figure 1.

A, The percentage of apoptotic tubular epithelial cells in the corresponding groups. B, The overexpression of Bcl-2/GAPDH in microdissected tubular cells from donor kidney biopsy specimens relative to cultured primary human tubular epithelial cells from healthy kidneys, which served as calibrator. Living donor kidneys (LIV) and cadaveric donor kidneys with primary function after transplantation (CAD-PF) expressed nearly 10-fold more Bcl-2 compared with cadaveric kidneys with subsequent acute renal failure $(C A D-A R F) .{ }^{*} p<0.05$. C, The relation between Bcl-2/GAPDH expression and the duration of cold ischemia. Prolonged cold ischemia was not associated with lower level Bcl-2 expression in cadaveric kidneys (PF as well as ARF). 
change on sequential renal biopsy specimens obtained at the beginning and the end of cold preservation. Cecka (2002) recently presented data from over 2300 organ donors from whom both kidneys were used for transplantation, but one kidney developed delayed graft function whereas the other kidney exhibited immediate graft function. The authors found that graded cold ischemia times of less than 36 hours did not adversely effect early graft function.

In the reperfusion phase after transplantation, however, active processes such as apoptosis reoccur. Burns et al (1998) showed a marked increase in apoptotic tubule cells after reperfusion of cadaveric grafts compared with the numbers obtained from prereperfusion biopsy specimens. A similar difference was not observed in living-related donor renal transplants. Furthermore, significantly more apoptotic tubule cells were observed in reperfusion cadaveric specimens compared with living donor transplants. Given the fact that cadaveric kidneys exhibit higher numbers of tubular apoptosis compared with living donor kidneys even before reperfusion, the higher incidence of postischemic ARF in cadaveric kidneys is not surprising.

Ortiz and coworkers (2000) studied the regulation of the Bcl-2 family members Bax, Bcl-xS, Bcl-2, and $\mathrm{Bcl}-\mathrm{xL}$ in animal models of ARF. The ratio of $\mathrm{Bcl}-2 / \mathrm{Bax}$ mRNA was decreased during ARF. Whole kidney RNA was used for this analysis. In the immunohistochemical studies, however, in which localization of protein expression was possible, the authors found a patchy distribution of pro- and antiapoptotic Bcl-2 members. In some tubules, the antiapoptotic $\mathrm{Bcl}-\mathrm{xL}$ was upregulated and $\mathrm{Bcl}-2$ was down-regulated, in other tubules it was the reverse (Ortiž et al, 2000). This differential expression in different sites of the tubules reflects the dissimilar vulnerability of diverse tubular sites to metabolic stress (Gobe et al, 2000). In the present study, we used only proximal tubules, which were identified by immunohistochemistry using an anti-CD13 antibody, and we analyzed the expression of the apoptosis regulators from the $\mathrm{Bcl}-2$ family from the same RNA. Therefore, an exact evaluation of the pro- and antiapoptotic differential regulation in this tubular segment was possible.

In summary, our data suggest that failure to respond to renal injury by tubular up-regulation of protective $\mathrm{Bcl}-2$ family members, especially $\mathrm{Bcl}-2$ itself, is associated with apoptotic tubular cell death and subsequent ARF and delayed allograft function in the recipient. $\mathrm{Bcl}-2$ overexpression might be of potential value as a preventive measure of postischemic ARF.

\section{Materials and Methods}

\section{Patients}

Between May 1998 and February 1999, 127 renal transplantations were performed at the University of Vienna Medical Center. One hundred one organs were procured from cadaveric, heart-beating donors, 8 from cadaveric, non-heart-beating donors, and 18 from living-related or emotionally related donors. A total of 107 recipients received their first allograft, 15 received their second allograft, and 5 received their third allograft. Eighteen patients were highly sensitized, as evidenced by panel-reactive antibodies of more than $25 \%$. Of these 127 patients, 101 fulfilled the study inclusion criteria, which were first transplantation, panel-reactive antibodies $<25 \%$, heart-beating donor and standard triple-drug immunosuppression. From these 101 patients, 36 participated in another study, 11 refused the biopsy in the first week after transplantation, and in 14 patients the core of the donor biopsy specimen or the first week biopsy specimen was either to small or of poor quality. Seven biopsy specimens could not be used because the core was not immediately frozen and the RNA was degraded.

The remaining 33 patients were clustered into one of three groups according to their immediate posttransplantation clinical course and the results of the transplant biopsy, which was obtained within the first 5 days. One group consisted of patients who received a kidney from a cadaveric donor and exhibited immediate transplant function (CAD-PF, $n=8$ ). The next group included recipients of a cadaveric kidney with postischemic ARF and biopsy-proven acute tubular damage but without signs of rejection (CAD-ARF, $n=$ 8). The third group included transplant recipients of living donors (LIV, $n=8$ ). None of the living donor kidneys exhibited ARF. If morphologic signs of acute rejection were evident, the patient was not included into the study $(n=9)$. Relevant donor and recipient data are listed in Table 1.

\section{Donor Kidney Biopsy Specimens}

All cadaveric and living donor kidneys were perfused with the histidine-tryptophan-ketoglutarate cold preservation solution at $4^{\circ} \mathrm{C}$ during organ procurement (Groenewoud and Thorogood, 1993). Wedge biopsy specimens were obtained under sterile conditions from all donor kidneys at the end of the cold ischemia time, immediately before transplantation. The biopsy specimen was immediately embedded in Tissue Tek (Sakure Finetek, Torrance, California), frozen in the gas phase of fluid nitrogen, and stored at $-80^{\circ} \mathrm{C}$ until further processing. Relevant donor data are given in Table 1.

\section{Laser Capture Microdissection}

Frozen biopsy specimens were cut on a cryostat microtome (Microme Heidelberg HM330) in 7- $\mu \mathrm{m}$ sections, and six sequential sections (three pairs) were mounted on glass slides covered with a 1.4- $\mu \mathrm{m}$ thin laser pressure catapulting membrane (P.A.L.M., Wolfratshausen, Germany). The laser pressure catapulting covering of the slides is necessary for optimal cutting and catapulting of microdissected tubules by the laser beam.

Immediately after taking the slides out of the freezer, the specimens were put into diethylpyrocarbonate 


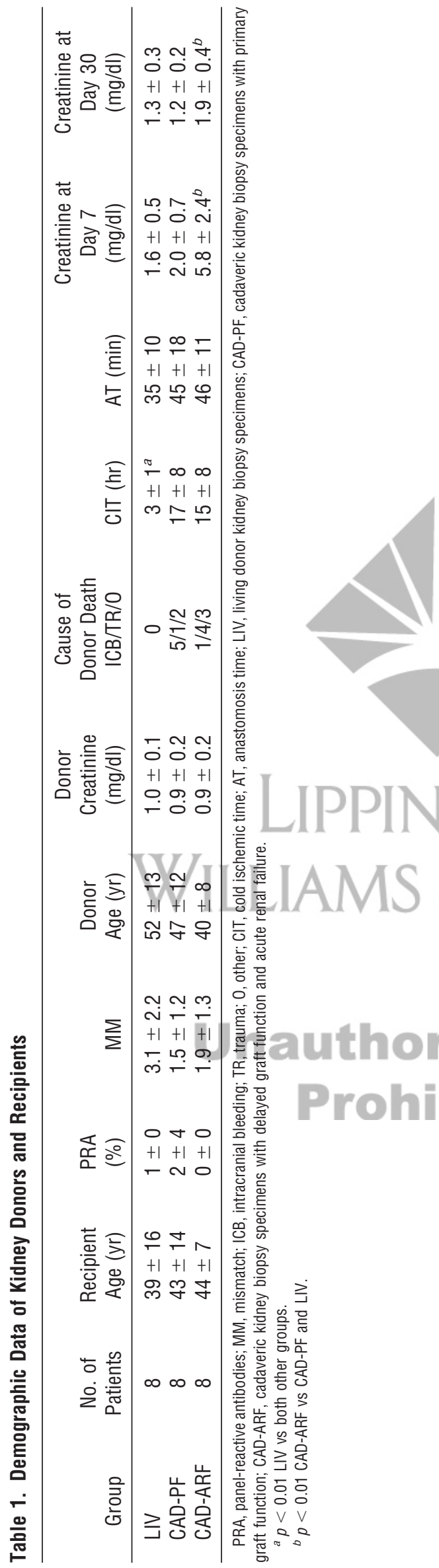

(DEPC)-treated water to remove the Tissue Tek. Proximal tubules were identified by immunohistochemistry using an anti-CD13 antibody (mouse monoclonal IgG2b; clone: 46A11; Diatec, Oslo, Norway). Because more than $90 \%$ of all RNA was degraded after immunohistochemistry, even if the time of the aqueous phase including the secondary antibody was cut down to less than 3 minutes, only one section of the pairwise mounted sequential sections was subjected to immunohistochemistry (Dako EnVision System, Carpinteria, California). The other section of the pair was stained with hemalum for 15 seconds. This immunohistochemically processed section served as template for the microdissection of proximal tubules in the hemalum-stained section (Fig. 2). An average of 100 proximal tubular cross-sections, containing roughly 1000 tubular cells, were isolated from the three hemalum-stained sections on each slide.

\section{Apoptosis Determination}

Apoptotic tubular epithelial cells were detected by using TUNEL staining (terminal deoxynucleotidyl transferase [TdT]-mediated dUTP nick end labeling) of fragmented DNA (Roche, Mannheim, Germany), as described by Gavrieli et al (1992). Briefly, samples were fixed with $4 \%$ formaldehyde for 20 minutes and then washed in PBS for 30 minutes. Afterward, permeabilization was performed by incubation with $0.1 \%$ Triton $X$ on ice for 2 minutes. The in situ nick end labeling of the fragmented DNA was performed by incubation with a mixture of fluorescein-labeled nucleotides diluted in TdT buffer in a humid dark chamber at $37^{\circ} \mathrm{C}$ for 60 minutes $(5 \mu \mathrm{l}$ of TdT and $45 \mu \mathrm{l}$ of hucleotides). An alkaline phosphatase-labeled antiFITC antibody (Converter AP, Boehringer Mannheim, Germany) was then added for 60 minutes; after 5 minutes of Fast Red incubation, which served as chromogenic substrate for the alkaline phosphatase, the samples were washed and counterstained with methylene green. At the end of the procedure, a coverslip was mounted. The negative controls were performed by omission of the TdT. Cryosections of reactive tonsils served as positive control. The number of TUNEL-positive cells (out of 1000 tubular epithelial cells counted) was recorded.

\section{RNA Isolation and Reverse Transcription}

RNA was isolated from microdissected tubules using the RNeasy Mini-Kit (Qiagen, Hilden, Germany). In brief, tubular cells were taken up in lysis buffer and treated with $1 \mu \mathrm{g}$ of polyA-carrier RNA (Qiagen). The lysate-carrier mix was dissolved in $70 \%$ ethanol and applied to a spin column. The RNA was eluted with 20 $\mu l$ of DEPC-treated water.

For first-strand cDNA synthesis, $20 \mu$ l of RNA was primed with $1.5 \mu \mathrm{l}(1 \mu \mathrm{g} / \mu \mathrm{l})$ of random hexamers (Gibco-BRL, Invitrogen, Karlsruhe, Germany) and subjected to heat denaturation $\left(3\right.$ minutes at $65^{\circ} \mathrm{C}$ ) and then put on ice. A 9- $\mu$ l reaction mix, containing $3 \mu$ l of $10 \times$ RT buffer, $20 \mathrm{~mm}$ dNTPs, $15 \mathrm{U}$ of RNaseOUT, and 

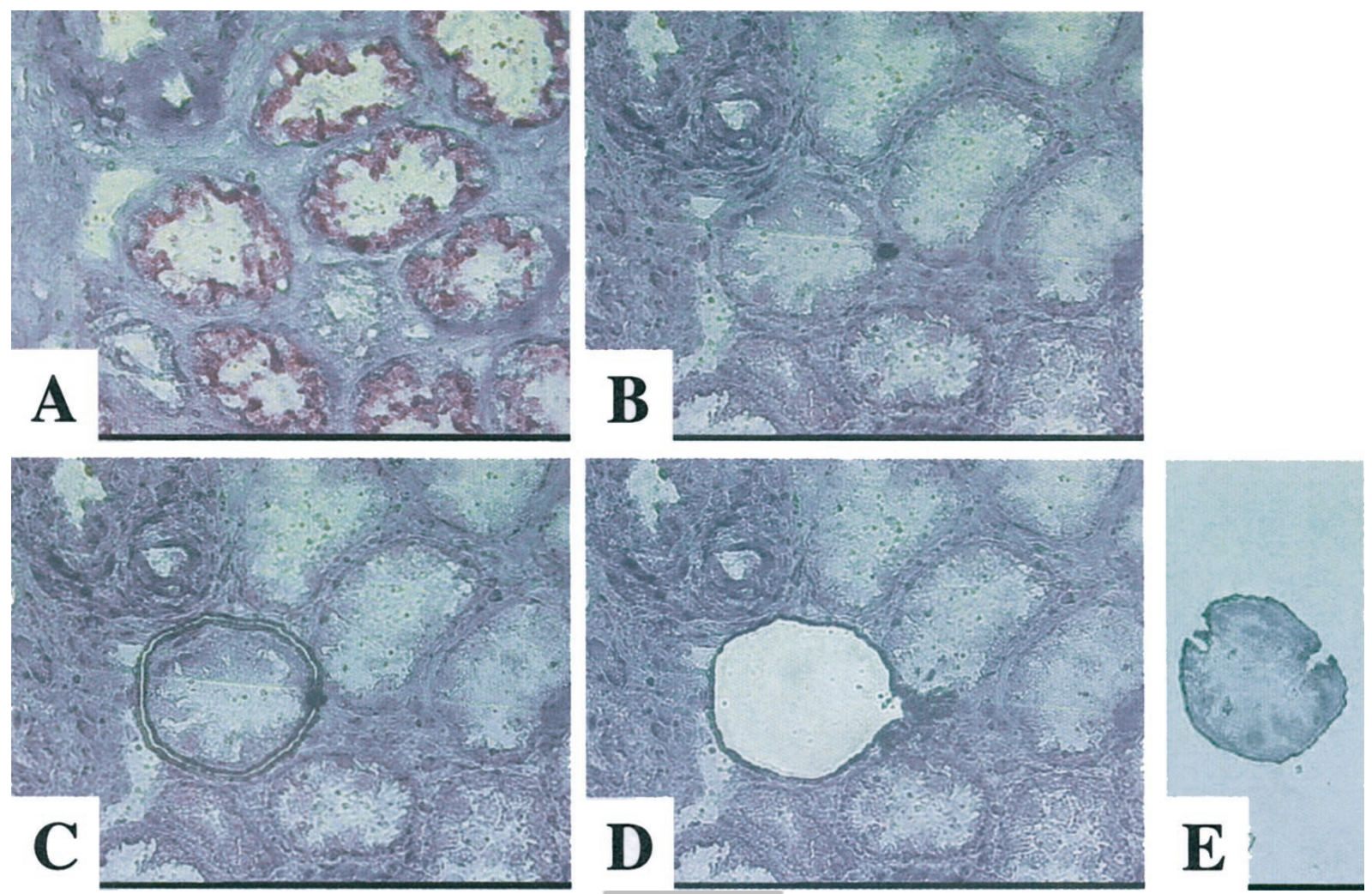

Figure 2.

Laser-captured microdissection of a proximal tubular cross-section from a cadaveric donor kidney biopsy specimen. A, Proximal tubule epithelial cells were identified by anti-CD13 (aminopeptidase-N) staining. Because the immunohistochemical procedure led to more than $90 \%$ degradation of RNA, consecutive tissue sections, stained only with hemalum, were used for microdissection. The immunohistochemically stained specimen served as template. B, Hemalum-stained consecutive section, $7 \mu \mathrm{m}$ apart from A. C, Circumferential microdissection of a tubular cross-section. D, Laser catapulting of dissected tubule. E, Isolated tubular cross-section that was used for RNA isolation (magnification $\times 800$ ).

6 U Sensiscript Reverse Transcriptase, was added and incubated at $37^{\circ} \mathrm{C}$ for 90 minutes (reverse transcriptase, dNTPs, and RT Buffer from Sensiscript RT Kit; Qiagen). Reverse transcriptase was inactivated thereafter by 10 minutes of incubation at $70^{\circ} \mathrm{C}$.

\section{Real-Time PCR}

For all PCR experiments, the ABI Prism 7700 Sequence Detector thermal cycler was used (Applied Biosystems, Foster City, California). Quantitative realtime PCR was performed according to the TaqMan protocol (Applied Biosystems). The antiapoptotic genes $\mathrm{Bcl}-2$ and $\mathrm{Bcl}-\mathrm{xl}$ and the proapoptotic gene Bax, as well as GAPDH, which served as endogenous standard, were amplified with predeveloped assays using the universal PCR mastermix (Applied Biosystems). The reaction mix consisted of $2.5 \mu \mathrm{l}$ of template volume, $12.5 \mu \mathrm{l}$ of mastermix, $1.3 \mu \mathrm{l}$ of predeveloped assay for either gene, and $8.7 \mu \mathrm{l}$ of DEPC-treated water.

The reaction conditions were as follows: after an initial phase of 2 minutes of warming up, samples were denatured at $95^{\circ} \mathrm{C}$ for 10 minutes; than 40 amplification cycles were performed at $95^{\circ} \mathrm{C}$ for 15 seconds and $60^{\circ} \mathrm{C}$ for 1 minute. The PCR reactions were performed in 96-well optical reaction plates (Applied Biosystems).
Sample preparation was performed in two separated PCR hoods for mastermix and template. All experiments were performed in triplicate.

\section{Quantification of Gene Expression}

Primary cultures of human renal proximal tubular epithelial cells, which were derived from nonaffected cortical areas of tumor-nephrectomy specimens, served as calibrator. The isolation, growth, and characterization of these cells were performed as described elsewhere (Baer et al, 1999; Pfaller and Gstraunthaler, 1998). The entire preparation was performed under sterile conditions in a laminar air flow. In brief, after mincing of the tissue with scalpels, a 30-minute step of collagenase digestion was performed, which was stopped with $2.5 \%$ BSA. The cell suspension was then squeezed through a sieve with 40- $\mu \mathrm{m}$ mesh, which was flushed three times with HBSS. Thereafter the cells were separated by a $37 \%$ Percoll gradient centrifugation at $15000 \mathrm{rpm}$ for 30 minutes at $4^{\circ} \mathrm{C}$. The band, which contained the tubule cells, was collected. After several washing steps, the cells were seeded onto fibronectin-coated cell culture dishes. Cells were grown in DMEM supplemented with $10 \%$ FCS, D-valine $(46 \mathrm{mg} / \mathrm{ml})$, linolic acid $(42 \mu \mathrm{g} / \mathrm{ml})$, thioctic-acid $(100 \mu \mathrm{g} / \mathrm{ml})$, and sodium-putrescine $(80$ $\mu \mathrm{g} / \mathrm{ml})$. Human proximal tubular epithelial cells were 
selected against fibroblasts through to the D-valine supplement in the growth media. Cultures were usually incubated at $37^{\circ} \mathrm{C}$ and $5 \% \mathrm{CO}_{2}$; for all proposed experiments, cell monolayers 3 to 6 days of age were used. Viability of cells was determined by light microscopy after trypan blue staining.

Tubular cells were characterized using proximal tubular markers such as HEA (Miltenyi Biotec, Gladbach, Germany), anti-CD13 antibodies (Aminopeptidase-N; Dako), angiotensin AT1 and AT2 receptor (Santa Cruz Biotechnology, Santa Cruz, California). and negative control staining with fibroblast-specific antibody (Dianova, Hamburg, Germany) followed by flow cytometric analysis.

RNA samples from cells derived from five different nephrectomy specimens were pooled to obtain a representative cross-section of human tubular gene expression in healthy tubular epithelial cells. All experiments were performed with the same calibrator RNA, which was stored in aliquots at $-80^{\circ} \mathrm{C}$. GAPDH served as internal standard.

Quantification of gene expression was performed according to the delta Ct method $\left(\Delta \mathrm{Ct}_{2} / \Delta \mathrm{Ct}_{1}\right)$, as described elsewhere (Jeyaseelan et al, 2001). Briefly, a ratio was calculated between the expression of the gene of interest to the expression of the internal standard (GAPDH) in the calibrator $\left(\Delta \mathrm{Ct}_{1}\right)$ and in the probe $\left(\Delta \mathrm{Ct}_{2}\right)$. Because the cDNA doubles in every PCR cycle, $2 \Delta^{\mathrm{Ct}}$ yields the $\mathrm{x}$-fold expression of the gene of interest compared with calibrator. The intraindividual coefficient of variation was below $1 \%$ in the calibrator samples and $15 \pm 9 \%$ in the microdissected donor kidney biopsy samples.

\section{Statistical Analysis}

Continuous variables were described by mean \pm SD, and correlations were calculated using the Spearman coefficient. The Kruskall-Wallis test or the Wilcoxon rank-sum test was used for the comparison between three or two groups, respectively. A $p$ value $<0.05$ was considered statistically significant. The SAS System V8.1 (SAS Institute Inc., 2000; Cary, North Carolina) was used for statistical analysis. All experiments were performed in triplicates, and the mean value was used.

\section{Acknowledgement}

The authors acknowledge the expert technical assistance of Mrs. Nicole Huttary with sample administration and Drs. Pfaller and Gstraunthaler with the isolation of the primary human tubular epithelial cells.

\section{References}

Baer PC, Tunn UW, Nunez G, Scherberich JE, and Geiger H (1999). Transdifferentiation of distal but not proximal tubular epithelial cells from human kidney in culture. Exp Nephrol 7:306-313.

Burns AT, Davies DR, McLaren AJ, Cerundolo L, Morris PJ, and Fuggle SV (1998). Apoptosis in ischemia/reperfusion injury of human renal allografts. Transplantation 66:872-876.
Cecka JM (2002). Does early injury have lasting impact? Presented at the ASTS Second Annual Winter Symposium, Bench to Bedside, Ischemia and Reperfusion Injury in Clinical Transplantation, January 25-27, Miami Beach, FL.

Cohen JJ (1993). Apoptosis. Immunol Today 14:126-130.

Cuttle L, Zhang XJ, Endre ZH, Winterford C, and Gobe GC (2001). Bcl-X(L) translocation in renal tubular epithelial cells in vitro protects distal cells from oxidative stress. Kidney Int 59:1779-1788.

Gavrieli Y, Sherman Y, and Ben-Sasson SA (1992). Identification of programmed cell death in situ via specific labeling of nuclear DNA fragmentation. J Cell Biol 119:493-501.

Gjertson DW (2000). Impact of delayed graft function and acute rejection on kidney graft survival. Clin Transpl :467480.

Gobe G, Zhang XJ, Willgoss DA, Schoch E, Hogg NA, and Endre ZH (2000). Relationship between expression of Bcl-2 genes and growth factors in ischemic acute renal failure in the rat. J Am Soc Nephrol 11:454-467.

Groenewoud AF and Thorogood J (1993). Current status of the Eurotransplant randomized multicenter study comparing kidney graft preservation with histidine-tryptophanketogluterate, University of Wisconsin, and Euro-Collins solutions. The HTK Study Group. Transplant Proc 25:15821585.

Hall BM, Tiller DJ, Duggin GG, Horvath JS, Farnsworth A, May J, Johnson JR, and Sheil AG (1985). Post-transplant acute renal failure in cadaver renal recipients treated with cyclosporine. Kidney Int 28:178-186.

Hariharan S, Johnson CP, Bresnahan BA, Taranto SE, Mclntosh MJ, and Stablein D (2000). Improved graft survival after renal transplantation in the United States, 1988 to 1996. N Engl J Med 342:605-612.

Jeyaseelan K, Ma D, and Armugam A (2001). Real-time detection of gene promoter activity: Quantitation of toxin gene transcription. Nucleic Acids Res 29:E58-8.

Koo DD, Welsh KI, McLaren AJ, Roake JA, Morris PJ, and Fuggle SV (1999). Cadaver versus living donor kidneys: Impact of donor factors on antigen induction before transplantation. Kidney Int 56:1551-1559.

Lieberthal W and Levine JS (1996). Mechanisms of apoptosis and its potential role in renal tubular epithelial cell injury. Am J Physiol 271:F477-F488.

Oberbauer R, Rohrmoser M, Regele H, Muhlbacher F, and Mayer G (1999). Apoptosis of tubular epithelial cells in donor kidney biopsies predicts early renal allograft function. J Am Soc Nephrol 10:2006-2013.

Oberbauer R, Schwarz C, Regele HM, Hansmann C, Meyer TW, and Mayer G (2001). Regulation of renal tubular cell apoptosis and proliferation after ischemic injury to a solitary kidney. J Lab Clin Med 138:343-351.

Ojo AO, Hanson JA, Meier-Kriesche H, Okechukwu CN, Wolfe RA, Leichtman AB, Agodoa LY, Kaplan B, and Port FK (2001). Survival in recipients of marginal cadaveric donor kidneys compared with other recipients and wait-listed transplant candidates. J Am Soc Nephrol 12:589-597.

Olsen S, Burdick JF, Keown PA, Wallace AC, Racusen LC, and Solez K (1989). Primary acute renal failure ("acute tubular necrosis") in the transplanted kidney: Morphology and pathogenesis. Medicine (Baltimore) 68:173-187. 
Oltvai ZN and Korsmeyer SJ (1994). Checkpoints of dueling dimers foil death wishes. Cell 79:189-192.

Oltvai ZN, Milliman CL, and Korsmeyer SJ (1993). Bcl-2 heterodimerizes in vivo with a conserved homolog, Bax, that accelerates programmed cell death. Cell 74:609-619.

Ortiz A, Lorz C, Catalan MP, Danoff TM, Yamasaki Y, Egido $\mathrm{J}$, and Neilson EG (2000). Expression of apoptosis regulatory proteins in tubular epithelium stressed in culture or following acute renal failure. Kidney Int 57:969-981.

Peherstorfer E, Mayer B, Böhm S, Lukas A, Hauser P, Mayer $G$, and Oberbauer R (2002). Effects of microinjection of synthetic $\mathrm{Bcl}-2$ family member domain peptides on apoptosis of renal tubular epithelial cells (Abstract). Am J Physiol Renal Physiol. [PDF] 10.1152/ajprenal.00317.2001. Available at: http://ajprenal.physiology.org/papbyrecent.shtml.

Pfaller W and Gstraunthaler G (1998). Nephrotoxicity testing in vitro: What we know and what we need to know. Environ Health Perspect 106:559-569.

Salahudeen AK, Huang H, Patel P, and Jenkins JK (2000). Mechanism and prevention of cold storage-induced human renal tubular cell injury. Transplantation 70:1424-1431.
Siehs C, Oberbauer R, Mayer G, Lukas A, and Mayer B (2002). Discrete simulation of regulatory homo- and heterodimerization in the apoptosis effector phase. Bioinformatics 18:67-76.

Van der Hoeven JA, Lindell S, van Schilfgaarde R, Molema G, Ter Horst GJ, Southard JH, and Ploeg RJ (2001). Donor brain death reduces survival after transplantation in rat livers preserved for $20 \mathrm{hr}$. Transplantation 72:1632-1636.

van der Hoeven JA, Ploeg RJ, Postema F, Molema I, de Vos $P$, Girbes AR, van Suylichem PT, van Schilfgaarde R, and Ter Horst GJ (1999). Induction of organ dysfunction and upregulation of inflammatory markers in the liver and kidneys of hypotensive brain dead rats: A model to study marginal organ donors. Transplantation 68:1884-1890.

van Valenberg PL, Hoitsma AJ, Tiggeler RG, Berden JH, van Lier HJ, and Koene RA (1987). Mannitol as an indispensable constituent of an intraoperative hydration protocol for the prevention of acute renal failure after renal cadaveric transplantation. Transplantation 44:784-788.

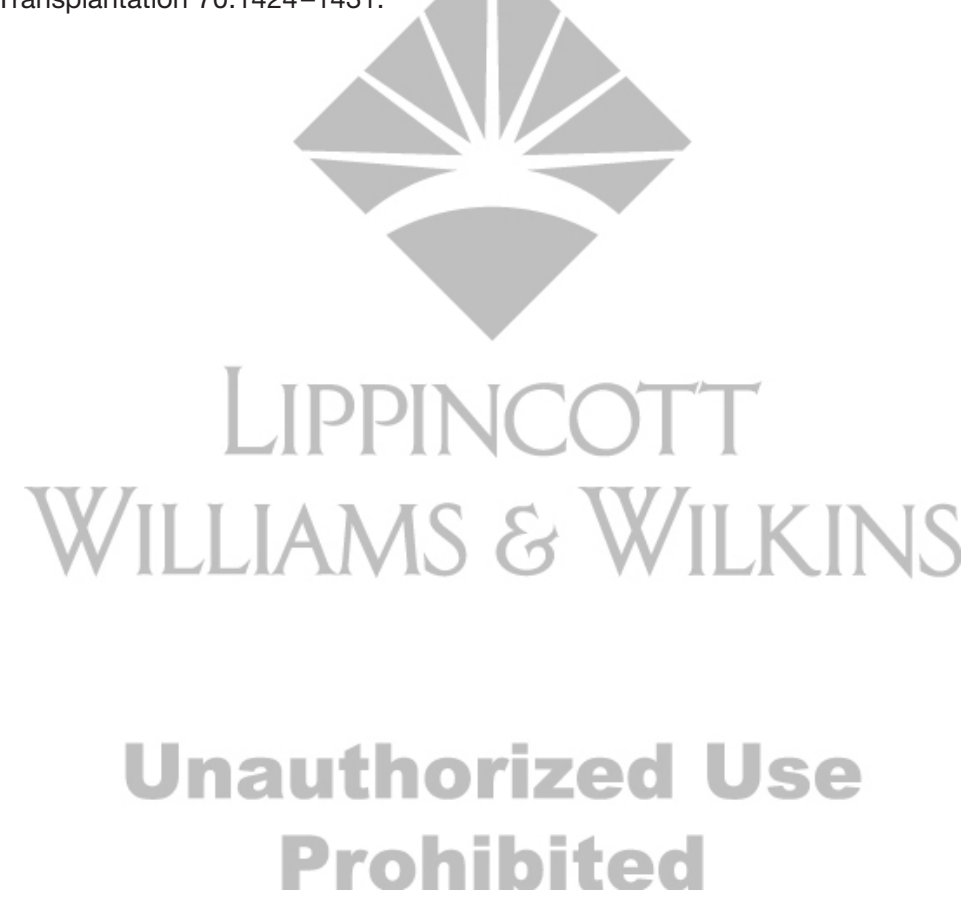

